\title{
The Evolution of Maintenance of Certification for Family Physicians (MC-FP) Part IV, Performance in Practice
}

\author{
Nichole Lainhart, BA, and Michael D. Hagen, MD
}

With the first recertification examination offered by the American Board of Family Medicine (ABFM) in 1976, the board required a patient record review to assess performance in practice. The initial records reviews required physicians to assess 4 patient records in each of 5 disease categories; these audits were independently scored by the family medicine department at the University of Iowa for the first several years. In 1983, the requirement was changed to assess 3 patient records in each of 2 disease categories. For the reviews, physicians audited individual patient charts and recorded approximately 100 items for each. In turn, the board analyzed these data then provided to Diplomates their individual performance data and peer comparisons, as well as a reference guide (which was a monograph that comprised a current review of the particular audit categories selected) and feedback with suggestions for improving performance. This process remained largely unchanged for 20 years.

In the late 1990s, the Institute of Medicine (IOM) released two seminal reports on patient safety, To Err is Human ${ }^{1}$ and Crossing the Quality Chasm, ${ }^{2}$ that heightened concern among constituencies such as the government, insurance companies, and advocacy groups over medical errors and quality of care. In response to these concerns, in 2000 the member boards of the American Board of Medical Specialties (ABMS; the parent body of the ABFM) adopted a formal process for continual professional development called Maintenance of Certification (MOC), which includes a performancein-practice component (Part IV). ${ }^{3}$

From the American Board of Family Medicine, Lexington, KY (NL, MDH); and the Department of Family and Community Medicine, University of Kentucky College of Medicine, Lexington (MDH).

Conflict of interest: The authors are from the ABFM.
Performance in practice. What does that mean? The ABFM defines it as "assessing a Diplomate's competence in systematic measurement and improvement in patient care." Clearly, this means more than the simplistic patient record review and feedback process that the board used previously.

When physicians review performance data, awareness of their performance can result in improvement; ${ }^{4}$ if not associated with systematic changes in practice, however, improvements likely will diminish over time. ${ }^{5}$ The performance-in-practice component of Maintenance of Certification for Family Physicians (MC-FP) is designed to deliberately support behavior or practice changes that produce sustainable improvements in patient care. By periodically assessing performance, setting an improvement goal, developing a plan for change, and implementing evidence-based improvements into practice (the Plan-Do-Study- $\underline{\text { Act }}$ cycle or other quality improvement methodology), ${ }^{6}$ physicians can systematically and sustainably improve the care they provide to patients. By completing this process as part of maintaining board certification, the board strives to assure the public that certified Diplomates possess the ability to identify shortcomings in practice and make substantive improvements to patient care.

In accord with the IOM reports' pleas for improvement in health care processes, not just measurement, the ABFM's Performance in Practice Modules (PPMs) were designed as a basic introduction to quality improvement, providing the tools and resources necessary to develop and implement a quality improvement plan. Between 2003 and 2009, the board developed 6 topic-specific modules (asthma, coronary artery disease, depression, diabetes, heart failure, and hypertension) and one comprehensive module that focused on preventive care measures across all ages and both sexes. They were intentionally designed to represent a basic intro- 
duction to quality improvement methodology, with the understanding that many health care organizations had already undertaken meaningful quality improvement work-efforts that in many cases represented more sophisticated approaches than those demonstrated in the PPMs-and that going forward we would need to develop a pathway for physicians to earn MC-FP credit for participating in these valuable activities.

In 2005 we began to develop an external provider pathway. Sponsors (eg, large practices, health systems, hospitals) that had implemented meaningful, structured quality improvement activities could apply to have single efforts considered as alternatives to the PPMs (between 20 and 25 programs currently apply each year). In 2008 we began working with the American Boards of Internal Medicine and Pediatrics to develop a pathway for sponsors that run multiple activities, which might involve multiple medical specialties, to create portfolios of activities that could be accepted as alternatives to the PPMs (the Multi-Specialty MOC Portfolio Approval Program; 17 ABMS member boards currently participate, 31 sponsor organizations have been approved, and 494 activities have been submitted [154 activities with family physician participation]).

These pathways serve as an excellent resource for our Diplomates. Each year, the portfolio of approved activities has grown, and thousands of physicians have been able to satisfy their MC-FP requirements using activities that relate more clearly to their practice contexts than the PPMs.

Even as these pathways took off and thrived, ABFM staff recognized that our current offerings overlooked another avenue for obtaining MC-FP Part IV credit. Many individual physicians participate in or develop quality improvement efforts that are not part of a larger organization or that have not been submitted to the ABFM for consideration as an approved alternative activity. To accommodate these activities, in 2011 we began to develop a self-directed pathway that would support both clinical and nonclinical activities (depending on the physician's work context) being considered for a Diplomate's Part IV requirement. The self-directed pathway enables physicians to describe spe- cific quality improvement work they have undertaken. The activities must meet the same standards and meaningful participation requirements as any other Part IV activity, but this pathway offers Diplomates the flexibility to develop or participate in activities that relate more clearly to their practice environment. To date more than 200 Diplomates have chosen this option to satisfy their Part IV requirement.

As the discipline of family medicine evolves, the need for more diverse, innovative avenues to assess performance in practice increases. We currently are planning a second-generation PPM that will provide a more user-friendly and robust process and are exploring other areas for alternative credit. These changes and new pathways notwithstanding, the ABFM's fundamental mission remains unchanged: to assure the public that board-certified family physicians possess the knowledge, skills, and professionalism necessary to provide the highest quality of care.

\section{References}

1. Kohn LT, Corrigan JM, Donaldson MS, eds. To err is human: building a safer health system. Washington, DC: National Academy Press; 2000. Available from: http://www.nap.edu/openbook.php?record_id=9728. Accessed March 31, 2014.

2. Institute of Medicine. Crossing the quality chasm: a new health system for the 21 st century. Washington, DC: National Academies Press; 2001. Available from: http://www.iom.edu/Reports/2001/Crossing-theQuality-Chasm-A-New-Health-System-for-the-21stCentury.aspx. Accessed March 31, 2014.

3. ABMS maintenance of certification. Chicago: American Board of Medical Specialties; 2012. Available from: http:// www.abms.org/Maintenance_of_Certification/ABMS_ MOC.aspx. Accessed March 31, 2014.

4. Ivers N, Jamtvedt G, Flottorp S, et al. Audit and feedback: effects on professional practice and healthcare outcomes. Cochrane Database Syst Rev 2012;6: CD000259.

5. Varkey P, Reller MK, Resar RK. Basics of Quality Improvement in Health Care. Mayo Clinic Proc 2007;82:735-9.

6. Langley GL, Nolan KM, Nolan TW, et al. The improvement guide: a practical approach to enhancing organizational performance, 2nd ed. San Francisco: Jossey-Bass Publishers; 2009. 